\title{
A Concentração Eleitoral no Brasil (1994-2014)*
}

George Avelino ${ }^{1}$

Ciro Biderman ${ }^{1}$

Glauco Peres da Silva ${ }^{2}$

1. Fundação Getulio Vargas (FGV), São Paulo, SP, Brasil. E-mail para contato: george.avelino@fgv.br.

2. Universidade de São Paulo (USP), São Paulo, SP, Brasil.

\section{INTRODUÇÃO}

$\mathrm{O}$

s efeitos do sistema eleitoral brasileiro e seu impacto na representação legislativa ainda são motivo de constante discussão, o que se expressa na perenidade do debate sobre a reforma política e as inúmeras propostas de mudança para diferentes aspectos do sistema.

Um dos temas mais comuns nesse debate tem sido a natureza e a extensão da concentração eleitoral dos candidatos, eixo das preocupações em explicar o comportamento legislativo dos eleitos através da conexão eleitoral (Mayhew, 1974). Na sua forma mais comum, este tipo de abordagem relaciona a concentração eleitoral - determinada por algum tipo de liderança pessoal e local - à produção legislativa do eleito; particularmente, às emendas orçamentárias e ao tipo de projetos apresentados. Destarte, a maioria das análises sobre a concentração foca nos candidatos eleitos, buscando relacionar seu perfil eleitoral - concentrado ou não concentrado - às suas atividades legislativas.

Nesse sentido, a compreensão sobre a extensão da concentração eleitoral entre os candidatos seria crucial para a compreensão do funciona-

\footnotetext{
* Agradecemos o inestimável auxílio de pesquisa proporcionado por Guilherme Lichand, Julia Guerreiro e Miguel Jacob, bem como as sugestões de dois pareceristas anônimos.

DADOS - Revista de Ciências Sociais, Rio de Janeiro, vol. 59, n-4, 2016, pp. 1091 a 1125.
} 
mento do sistema político. Por exemplo, um sistema político baseado em partidos cujos membros representam interesses geograficamente localizados tenderia a favorecer políticas que permitam direcionar os gastos para atender àqueles interesses. Por outro lado, se a representação partidária é voltada para interesses mais amplos, as políticas favorecidas seriam aquelas cujos benefícios sejam mais universais e agregados.

O propósito do artigo é dar um passo atrás nessa discussão e analisar melhor o que se entende por concentração eleitoral; reconhecidamente, um aspecto crítico para a compreensão dos impactos do sistema eleitoral de lista aberta sobre as estratégias dos partidos e seus candidatos. Se existe alguma relação entre o perfil eleitoral e a atuação do parlamentar, a solução desta questão remete à especificação do perfil do candidato. Para que isto seja possível, é necessário definir o que entendemos por concentração eleitoral e adotar medidas que sejam adequadas a essa definição, de forma a comparar o grau de concentração eleitoral entre todos candidatos - eleitos e não eleitos. Assim, a distribuição de votos de um candidato - e seu perfil eleitoral concentrado ou disperso - resulta de dois aspectos que, embora relacionados, precisam ser separados. O primeiro é a distribuição dos eleitores entre os municípios do estado. O segundo aspecto, núcleo de interesse dos trabalhos voltados para a conexão eleitoral, são as estratégias empregadas pelos candidatos na disputa pelos votos.

Com este objetivo, é retomado o índice sugerido por Avelino, Biderman e Silva (2011), que separa os dois componentes da concentração eleitoral, e originalmente utilizado para analisar os candidatos paulistas. Neste artigo, este índice é testado para os candidatos a deputado federal nas eleições compreendidas nos últimos vinte anos - entre 1994 e 2014 - para todos os estados brasileiros. Além disso, a adoção desta medida permite explorar diferentes estratégias eleitorais dos candidatos, sejam estas últimas voltadas para bases de eleitores locais, regionais ou estaduais.

Os resultados de uma avaliação preliminar indicam clara diferença entre a concentração eleitoral dos candidatos eleitos e dos não eleitos. $\mathrm{Na}$ maioria dos casos, os que conseguem se eleger tendem a ter seus votos muito mais dispersos do que aqueles que falham na tentativa. Um segundo achado importante é que, ao contrário do suposto pela literatura sobre concentração de votos, a unidade de análise mais adequada 
para medir a concentração não é o município, mas a microrregião. Isso porque a concentração não se esgota no município; mas, segue crescendo conforme ampliamos a unidade de análise para a microrregião. $\mathrm{O}$ mesmo crescimento não acontece quando ampliamos para uma unidade de análise mais ampla, tal como a mesorregião, ou seja, não há diferença significativa entre os índices de concentração na escala da microrregião e na escala da mesorregião. Este achado questiona o suposto da "distritalização" do voto, na qual a influência de um candidato cresceria de forma contígua a partir do município original de concentração.

Este artigo, além desta breve introdução, está organizado em cinco partes. A segunda parte é dedicada à discussão do conceito de concentração eleitoral e sua definição como resultado das estratégias eleitorais empregadas pelos candidatos; particularmente, a construção das candidaturas através do voto pessoal. A terceira apresenta a nova medida, mais adequada à definição de concentração eleitoral e possuidora de atributos estatísticos, que permitem estabelecer diferenças significativas entre os perfis dos grupos de candidatos. Outra vantagem importante da nova medida é permitir a variação da unidade territorial da análise para abranger as regiões - conjuntos integrados de municípios - como os espaços privilegiados pelos candidatos nas suas atividades eleitorais. A quarta apresenta comparações dos níveis de concentração eleitoral entre todos os candidatos a deputado federal nas últimas seis eleições. Finalmente, a quinta parte sumariza e conclui.

\section{O ESTUDO DA CONCENTRAÇÃO ELEITORAL NO BRASIL}

As primeiras discussões sobre a concentração eleitoral no Brasil partiram do desconforto dos analistas com as características dos candidatos eleitos no sistema proporcional. Embora o sistema proporcional tivesse sido adotado para limitar os efeitos do localismo na política brasileira, o que se observava era um padrão de competição eleitoral ainda marcado pelos aspectos locais, prejudicando a representação dos interesses mais amplos. Dentro desta abordagem, localismo, paroquialismo e conservadorismo eram tratados como conceitos equivalentes; em contraste, os candidatos com votação dispersa seriam mais "ideológicos", ou seja, tenderiam a representar interesses mais "universais"1. Tal como sugerido por Carvalho: 
O comportamento politico a se evitar, para esse conjunto de autores, apresentava, então, uma clara tradução no espaço geográfico: a política atrasada e não ideológica seriam atributos dos representantes com votação concentrada. Ora, não custa lembrar que, em termos muito semelhantes e anos mais tarde, os teóricos distributivistas iriam estabelecer igual nexo entre o localismo na arena eleitoral e o paroquialismo na esfera legislativa (2003:94; ênfases no original).

Aos poucos, a questão específica da distribuição geográfica do apoio eleitoral dos candidatos vai ocupando mais espaço na discussão. Assim, logo em meados dos anos 1970, são publicados os trabalhos de David Fleischer (1976 e 1981) sobre a composição da bancada mineira eleita nas primeiras eleições sob o bipartidarismo. No mesmo contexto, a bancada paulista eleita em 1978 é analisada por Indjaian (1981 apud Lamounier, 1982) e a eleita em 1986, já sob competição multipartidária, por Kinzo (1989); por sua vez Dias (1991) analisa o perfil eleitoral dos candidatos eleitos no Rio de Janeiro nas eleições de 1986 e 1990. De forma geral, o objetivo destes trabalhos é apenas a descrição do perfil eleitoral dos eleitos - concentrados ou dispersos - e os padrões da competição partidária.

Como era de se esperar, as medidas sugeridas por estes autores variam bastante tanto nas suas unidades de análise - municípios e zonas eleitorais - como pressuposições sobre o uso do espaço geográfico. Com relação a este último ponto, é possível identificar pelo menos duas perspectivas relacionadas na definição do perfil eleitoral dos candidatos. A primeira, mais normativa, já a pontada anteriormente, foca simplesmente na ausência da dispersão dos votos que seria esperada em sistemas eleitorais proporcionais. Mais especificamente, o pressuposto básico desta perspectiva é a oposição entre o voto local - mais "conservador" e relacionado à pobreza e aos baixos níveis de urbanização ao voto "nacional" (mais "ideológico" e urbano) que deveria representar as preferências de eleitores dispersos no distrito. A segunda perspectiva se baseia em análises mais detalhadas das votações dos candidatos e aponta para a possível "distritalização" do voto, que estaria ocorrendo independentemente do sistema eleitoral e, portanto, pressupõe a contiguidade espacial dos votos concentrados.

Em suma, a preocupação volta-se para a descrição da distribuição espacial dos votos dos eleitos e o grau de representatividade do Legislativo. A análise do perfil eleitoral dos candidatos mostraria que o siste- 
ma proporcional brasileiro não só seria incapaz de dar voz a interesses dispersos geograficamente, como estaria sendo subvertido pelos interesses locais que imporiam uma "distritalização" não regulada - ou no dizer dos autores, "informal" - da representação política. Em geral, neste período não existe preocupação em entender a concentração eleitoral como produto de estratégias empregadas pelos candidatos; tema característico do período posterior.

\section{Estratégia e Conexão Eleitoral}

A discussão mais recente acerca da influência do sistema eleitoral sobre o comportamento dos políticos no Brasil, sem abandonar a discussão do perfil eleitoral, procurou enfocar na concentração como resultado de estratégias eleitorais empregadas pelos candidatos em um sistema de representação proporcional por lista aberta, bem como os reflexos dessas estratégias no comportamento dos eleitos.

Como é sabido, os sistemas eleitorais contêm regras que influenciam vários aspectos do sistema político, tal como o número de partidos, o tipo de candidato e também as estratégias eleitorais. Como lembrado por Cox (1990 e 1997; ver também Cox e Shugart, 1996), os sistemas proporcionais não encorajam a busca da maioria dos eleitores, tal como nos sistemas majoritário; ao contrário, nestes sistemas os partidos e candidatos são encorajados a buscar pequenos grupos de eleitores. Além disso, em um sistema de lista aberta, essa característica do sistema proporcional abriria espaço para diferentes tipos de estratégias eleitorais.

O primeiro passo para a discussão das estratégias eleitorais no caso brasileiro foi dado por Scott Mainwaring $(1991,1999)$. Segundo este autor, o sistema eleitoral brasileiro - representação proporcional de lista aberta, associado a distritos de grande magnitude - estimularia a disputa intrapartidária e incentivaria a ação individual dos candidatos na tentativa de se diferenciar de seus concorrentes ${ }^{2}$. Assumida a fraqueza dos partidos, os candidatos teriam de voltar-se para estratégias eleitorais que privilegiassem o "voto pessoal" (Cain, Ferejohn e Fiorina, 1987) em detrimento do voto partidário. De forma geral, o suposto é que a busca do "voto pessoal" implicaria em concentração de votos.

A perspectiva da estratégia do "voto pessoal", e sua importância na explicação da concentração eleitoral, é aperfeiçoada pelos trabalhos de 
Barry Ames (1995a; 1995b e 2001), que traz para o debate sofisticação teórica e evidências empíricas mais consistentes. Do ponto de vista teórico, a pressuposição da fraqueza dos partidos leva à especificação das estratégias eleitorais individuais e os incentivos dados pelo sistema eleitoral para os candidatos optarem por certo tipo de estratégia. Empiricamente, o trabalho ressalta a importância da distribuição geográfica dos votos dos candidatos através de coleta de dados eleitorais municipais ${ }^{3}$. A análise da distribuição dos votos de um candidato permitiria traçar o seu perfil eleitoral e prever sua eventual atuação parlamentar, estabelecendo de forma mais precisa a conexão eleitoral brasileira ${ }^{4}$.

Em um sistema eleitoral de lista aberta, os candidatos usualmente precisam de dois estimadores cruciais para determinar suas estratégias eleitorais: o primeiro é sobre o desempenho geral da lista de candidatos de seu partido (ou coligação), determinante para saber o número provável de vagas a serem conquistadas. O segundo estimador é sobre o desempenho individual dos outros candidatos, o que determinará sua posição na lista. Como apontado por Cox (1997), distritos de grande magnitude dificultam qualquer estimativa mais precisa tanto sobre o desempenho esperado das listas como sobre desempenhos individuais, gerando incerteza eleitoral entre os candidatos. Por outro lado, distritos de grande magnitude implicam também que os candidatos não precisam fazer campanha sobre todo o território (Ames 1995a, 2001); mas, podem se eleger com votações concentradas em espaços menores (municípios ou regiões) ${ }^{5}$. Conjugada com a incerteza eleitoral, estas condições motivariam os candidatos na busca por nichos geográficos de eleitores.

Como seria esperado, a distribuição dos eleitores entre os municípios de seu estado influencia a estratégia eleitoral dos candidatos. Por exemplo, os custos de campanha devem ser menores se os eleitores estão mais agregados; portanto, regiões mais densamente povoadas devem ser objeto de disputa mais intensa entre os candidatos ${ }^{6}$. Além disso, dada a configuração da rede urbana brasileira, existem poucos municípios cujo número de eleitores seria igual ou superior ao quociente eleitoral dos respectivos estados ${ }^{7}$, o que poderia justificar o esforço de concentração municipal.

Segundo Ames, frente a magnitude dos distritos e o acesso escasso aos meios de comunicação de massa, normalmente reservados para as dis- 
putas majoritárias, a maioria dos candidatos optaria por concentrar seus recursos eleitorais em áreas restritas como forma de reduzir os custos da campanha. Desta forma, a estratégia dominante dos candidatos seria concentrar recursos em determinadas regiões, o que resultaria no perfil concentrado de votos.

O voto pessoal estaria implícito na constatação de que a área de concentração dos esforços de campanha não seria escolhida de forma aleatória; mas, deveria privilegiar áreas nas quais o candidato já tivesse seu nome reconhecido como liderança local. Em outras palavras, o tipo de candidato mais eficiente deveria ser aquele com uma liderança local - e pessoal - o que presumivelmente aumentaria a credibilidade das promessas do candidato e facilitaria a persuasão dos eleitores. O perfil espacialmente concentrado, portanto, teria por base aquela liderança pessoal, cujo alcance poderia ser ampliado do município central (core) para as áreas contíguas pelos recursos de campanha, aumentando as chances de vitória do candidato ${ }^{8}$.

Para medir a concentração, o indicador sugerido por Ames tinha um componente distributivo, que opunha a dominância - o controle eleitoral de um determinado município, expresso através da fração de eleitores conquistada pelo candidato - ao compartilhamento; e um componente geográfico, que opunha a concentração à dispersão ${ }^{9}$. Para estimar o componente geográfico, embora não apresente estatísticas descritivas, Ames sugere o uso do índice "I" de Moran que busca correlações espaciais entre área adjacentes com o intuito de tentar avaliar o grau de contiguidade da concentração eleitoral dos candidatos.

A despeito da importância da contribuição de Ames, os indicadores propostos para mensurar a concentração de votos não foram objeto de muita discussão. Uma parte de literatura abandona a questão da contiguidade espacial ao sugerir indicadores baseados no número de municípios nos quais o parlamentar obteve sua votação ${ }^{10}$. Outra parte da literatura procura identificar o município central (core); assim, a discussão sobre o caráter contíguo ou não dos municípios nos quais o candidato concentraria seus votos dá lugar a simplicidade metodológica de indicar o município com mais destaque nas votações dos candidatos $^{11}$. Supostamente, este município representaria mais claramente o "distrito informal", onde se localizariam os eleitores mais fiéis e para os quais deveriam ser dirigidos os recursos administrados pelos deputados, fechando o círculo da conexão eleitoral brasileira. A questão ób- 
via, nesse caso, é a extrapolação das informações relativas à votação do candidato em um único município para a votação deste mesmo candidato no estado como um todo ${ }^{12}$.

De certa forma, portanto, o sacrifício do componente geográfico - o grau de contiguidade dos municípios em que os candidatos concentram seus votos - em prol da identificação do município central para a votação do candidato se apoia e reforça a presunção, ainda teoricamente obscura, de que os candidatos obtêm mais votos onde exercem uma liderança que mistura aspectos locais e pessoais. Duas objeções podem ser feitas aqui. A primeira, mencionada anteriormente, é que poucos municípios congregam um número de eleitores igual ou superior ao quociente eleitoral do estado. A segunda objeção, tal como reconhecida por autores como o próprio Ames (1995a e 2001) e Carvalho (2003) é que, dada a evolução da competição no sistema partidário brasileiro, a dominância, o componente distributivo do indicador de Ames, definido pelo percentual de votos dos candidatos nos municípios, estava em declínio. Assim, o padrão concentrado e dominante, que caracterizaria mais fortemente os candidatos "locais", estaria em extinção.

Em resumo, para se avançar na análise dos efeitos das estratégias eleitorais dos candidatos a deputado, a relação teórica entre a fraqueza dos partidos, o voto pessoal e a concentração eleitoral, precisa ser esclarecida. Este avanço teórico, entretanto, requer medidas e análises mais precisas em pelo menos três aspectos. O primeiro é separar a distribuição dos votos dos candidatos entre os componentes resultantes da distribuição dos eleitores no estado e os componentes que resultam da estratégia eleitoral dos candidatos. O segundo aspecto é recuperar o componente geográfico da concentração, tal como sugerido por Ames. Finalmente, o terceiro e último aspecto é envolver todos os candidatos na análise, e não apenas os eleitos, de maneira a poder especificar as estratégias eleitorais destes últimos com relação aos candidatos não eleitos. A próxima seção deste artigo dedica-se a explicar o índice " $G$ ".

\section{0 ÍNDICE " $G$ "}

Na seção anterior, verificamos que a discussão da concentração, e obviamente, suas sugestões de medidas, tem início com a preocupação sobre a inadequação descritiva da representação engendrada pelo sistema proporcional - local ou nacional - e sua relação com aspectos sociais e econômicos; passando pela sugestão da adoção do sistema dis- 
trital como o mais adequado para, finalmente, desembocar no atual debate que vincula concentração à conexão eleitoral e ao comportamento legislativo dos eleitos.

Também como visto, o tamanho dos distritos brasileiros abre espaço para estratégias eleitorais diversas. Diferentemente dos sistemas distritais simples, em que o eleitorado está geograficamente localizado por lei e o objetivo dos candidatos é conquistar a maioria dos eleitores, os candidatos no Brasil podem adotar diferentes estratégias em diferentes áreas do estado. Onosso objetivo é dar um passo atrás e especificar o grau de concentração eleitoral como produto das escolhas de estratégias, ou seja, de escolhas sobre a utilização dos recursos eleitorais dos candidatos ${ }^{13}$. O esclarecimento deste ponto é fundamental para a análise da conexão eleitoral brasileira.

Para tanto é necessário decompor a concentração eleitoral entre a parte relacionada à distribuição dos eleitores entre os municípios do estado e a parte derivada da utilização de estratégias eleitorais. Por exemplo, se um candidato adotasse uma estratégia de campanha de dividir todos os seus recursos de forma proporcional à distribuição do eleitorado nos municípios do estado, seus votos, em média, também deveriam estar distribuídos da mesma maneira. Se, por outro lado, o candidato adotasse uma estratégia de concentrar seus recursos em apenas uma área, os votos naquela área deveriam ser proporcionalmente maiores do que o esperado em comparação com a distribuição do eleitorado, o que aumentaria o valor de um índice de concentração apto a capturar as diferenças entre aquelas escolhas.

Tal como em Avelino, Biderman e Silva (2011), este trabalho propõe a adaptação de um índice amplamente utilizado na literatura de economia regional para identificar o grau de concentração geográfica dos setores. Este índice, geralmente denominado por "G" (também a denominação adotada neste artigo), foi utilizado pela primeira vez na literatura de ciências regionais por Florence (1947) ao analisar os determinantes da concentração de setores econômicos nas regiões. De fato, a discussão sobre a concentração da atividade econômica se inicia nesse período e foi amplamente utilizada nas pesquisas em ciências regionais ${ }^{14}$.

Mais recentemente, Ellison e Glaeser (1997) recuperaram o interesse no índice utilizando-o em associação com um índice clássico da organização industrial, o chamado índice de Herfindal-Hirshman (também conhecido por $\mathrm{HH}$ ). Os autores desenvolveram um indicador de 
concentração geográfica do emprego industrial a partir "abordagem dos alvos de dardos" (dartboard approach). Esta abordagem parte da analogia entre a concentração do emprego e a distribuição de dardos, jogados aleatoriamente - sem alvo específico, portanto - em um mapa. Nessa situação, seria de se imaginar que as regiões maiores no mapa recebessem um número maior de dardos. Estendendo a mesma analogia para os resultados eleitorais, seria de se esperar que, sem estratégia eleitoral, os votos de cada candidato deveriam se distribuir aleatoriamente de acordo com a distribuição geográfica dos eleitores entre os municípios do estado. Em outras palavras, se as áreas do mapa forem de tamanho proporcional à distribuição dos eleitores, municípios com mais eleitores deveriam ser preponderantes em uma distribuição aleatória de votos com relação aos municípios com menos eleitores ${ }^{15}$.

Desta forma, seguindo Avelino, Biderman e Silva (2011), a adaptação proposta neste artigo pode ser definida como:

$$
G_{d} \equiv \sum_{m}\left(\frac{V_{d m}}{V_{d}}-\frac{V_{m}}{V}\right)^{2}
$$

Em que:

$v_{d m}-$ votos do deputado $d$ no município $m$

$v_{d} \equiv \sum_{m} v_{d m}$ - total de votos do deputado $d$ (somatório dos votos no deputado $d$ em cada um dos municípios do estado)

$v_{m} \equiv \sum_{d} v_{d m}$ - total de votos dos deputados no município $m$ (somatório dos votos de cada um dos deputados no município $m$ )

$V \equiv \sum_{d} \sum_{m} V_{d m}$ - total de votos de todos os deputados no estado (somatório dos votos de cada um dos deputados em cada um dos municípios do estado)

Dadas as características políticas e administrativas dos distritos estaduais brasileiros, a ênfase nos municípios como ponto de partida para análise da concentração eleitoral é natural e a nossa medida, assim como outras, respeita isso ao focar nos municípios e, como veremos, em agregações de municípios. De forma simples e de fácil operacionalização, o índice deduz dos votos observados para um dado deputado, em um determinado município, da votação que seria esperada para esse mesmo deputado, no mesmo município, caso os votos fossem distribuídos de maneira aleatória, ou proporcional ao número de eleitores 
entre os municípios. Uma maneira intuitiva de entender este índice é observando que se um deputado tivesse os seus votos distribuídos exatamente de acordo com a distribuição dos eleitores entre os municípios do estado, o valor do seu índice "G" seria igual a zero.

Por exemplo, é esperado que um candidato qualquer no Amapá obtenha quase $60 \%$ de votos no município de Macapá, pois quase $60 \%$ do eleitorado do estado se concentra nesse município. Se, por outro lado, um candidato adotasse uma estratégia de concentrar seus recursos massivamente em Macapá, seria esperado que ele obtivesse nesse município uma proporção de votos superior a $60 \%$. O índice " $G$ ", portanto, captura os resultados dos investimentos eleitorais dos candidatos em determinadas áreas, investimentos que determinariam a concentração dos votos.

Outra vantagem do índice "G" é a apresentação de um contrafactual explícito, ou seja, o caso em que a votação do candidato apresenta exatamente a mesma distribuição geográfica que a do eleitorado. De volta ao exemplo do parágrafo anterior, não é possível afirmar que um candidato acumulando quase $60 \%$ de seus votos em Macapá tenha uma distribuição concentrada de votos, o que poderia potencialmente ocorrer com outros índices utilizados na literatura ${ }^{16}$. Além disso, o fator quadrático no cálculo do índice torna possível que desvios abaixo ou acima da proporção do eleitorado sejam contabilizados da mesma forma, o que permite o cálculo da variância e, como veremos adiante, a verificação de diferenças estatisticamente significantes entre os grupos de candidatos ${ }^{17}$.

Para ajudar a compreensão do índice, abaixo seguem os mapas com os resultados das eleições de 2014 para dois candidatos com valores extremos, escolhidos entre as seis eleições analisadas neste artigo: um entre os mais desconcentrados eleitoralmente e outro entre os mais concentrados. Para facilitar a leitura dos mapas, e de acordo com a definição de concentração defendida neste artigo, é utilizado o Quociente Locacional (QL), outro indicador adaptado das ciências regionais ${ }^{18}$. Nesse caso, o QL de um candidato por município é determinado pela razão entre duas proporções: a proporção dos votos obtidos no município com relação à votação total do candidato, e a proporção de eleitores do município no eleitorado do estado, ou seja, a votação esperada do candidato naquele município ${ }^{19}$. De leitura fácil, quando o QLé de valor um, isso indica que o candidato obteve a votação que seria esperada 
naquele município, caso os votos fossem distribuídos aleatoriamente. Da mesma forma, QLs abaixo de um indicam uma votação inferior ao esperado e QLs acima de um indicam votações acima do esperado.

O candidato mais desconcentrado, cujo mapa pode ser observado na Figura 1, é Marco Antônio Feliciano - com G igual a 0,001 - eleito pelo PSC do São Paulo e protagonista importante nos debates sobre a extensão dos direitos individuais na Câmara dos deputados. De acordo com os dados do mapa, o candidato não teve nenhuma votação local estrondosa e espalhou seus 398 mil votos entre 644 de 645 municípios do estado. O único município onde o candidato não teve votos, o pequeno ponto branco no extremo noroeste do mapa abaixo que denota a "aldeia gaulesa" do estado, foi Turmalina que, segundo a apuração, contou com 1.183 votos válidos para deputado federal.

O candidato escolhido entre os mais concentrados de todas as eleições, representado na Figura 2, foi Odelmo Leão - cujo G é igual a 0,797 eleito pelo PP de Minas Gerais, e que concentra seus quase 180 mil votos na região em torno do município de Uberlândia, do qual havia sido prefeito até 2012. Este seria um caso clássico de deputado concentrado

Figura 1

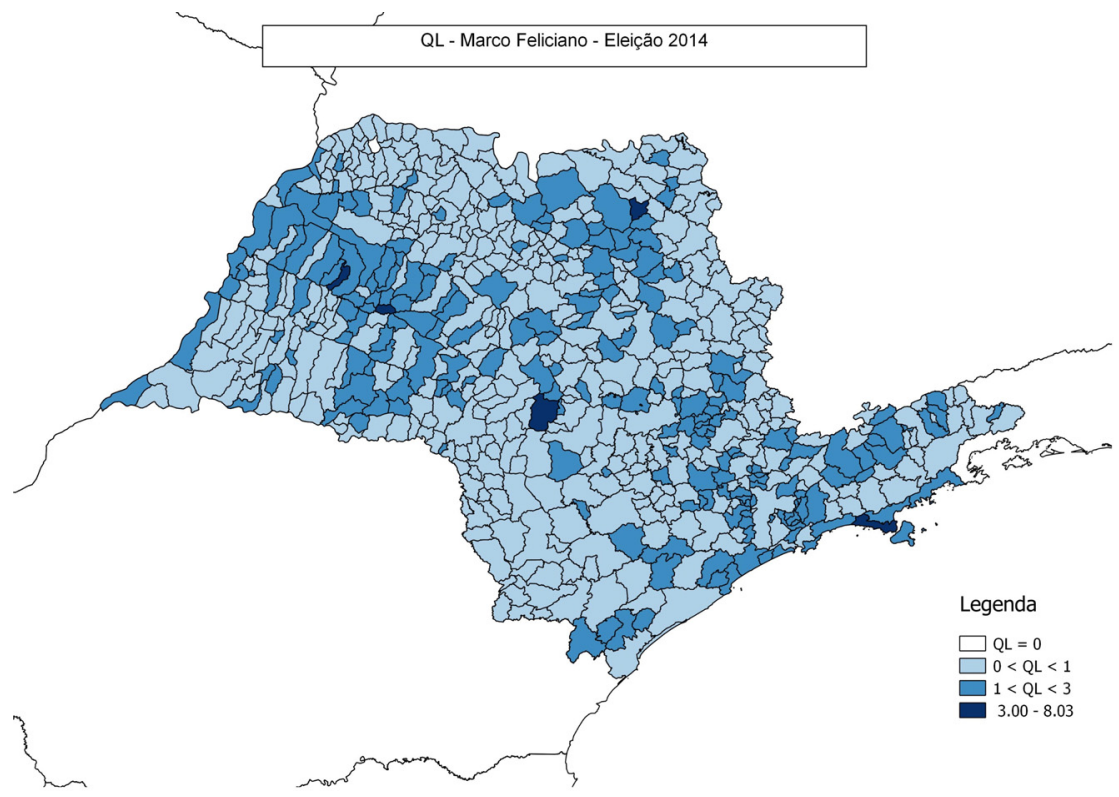

Fonte: Tribunal Superior Eleitoral/CEPESPDATA. 
Figura 2

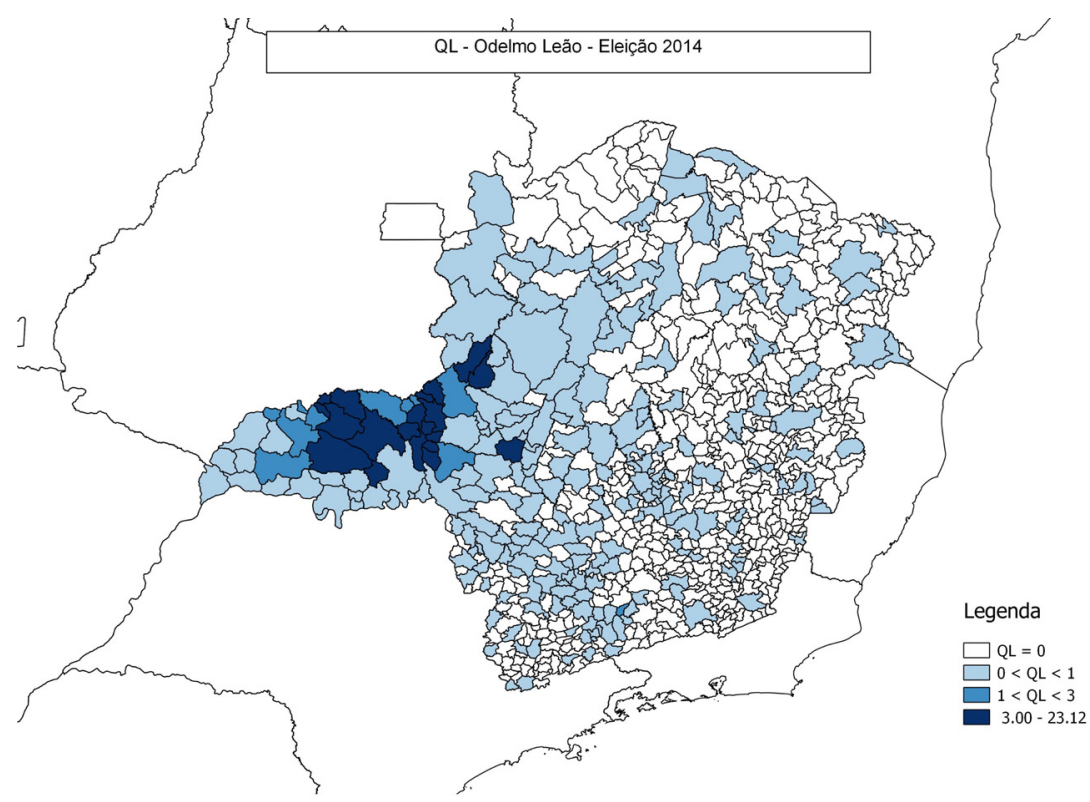

Fonte: Tribunal Superior Eleitoral/Cepespdata.

em um município - QLs indicam que em alguns municípios, a votação obtida foi mais de 23 vezes a votação esperada - cuja influência eleitoral se espalha para os municípios vizinhos.

O índice "G", portanto, traz avanços conceituais e metodológicos importantes com relação aos indicadores anteriores. Do ponto de vista conceitual, ao apresentar um contrafactual claro e consistente, ele permite especificar a concentração eleitoral como resultado de estratégias dos candidatos, entendidas com decisões sobre aplicação de recursos eleitorais escassos. Do ponto de vista metodológico, ao realizar ao especificar a parte da concentração que pode ser interpretada como o resultado de estratégias eleitorais, o índice ameniza o problema de inferir escolhas de estratégias eleitorais a partir da análise da distribuição dos votos. Além disso, ao apresentar atributos desejáveis do ponto de vista estatístico, ele permite inferências mais precisas. Em suma, o índice proposto é mais fundamentado que os esforços anteriores em avaliar a distribuição de votos dos parlamentares. A próxima seção amplia o uso do "G" para conjunto dos candidatos brasileiros nas eleições realizadas entre 1994 e 2014, o que permite comparações mais consistentes entre as estratégias eleitorais dos candidatos. 


\section{COMPARANDO 0 GRAU DE CONCENTRAÇÃO ELEITORAL ENTRE OS CANDIDATOS A DEPUTADO FEDERAL}

Antes de apresentar os resultados, é necessário ressalvar que, coerentemente com a legislação eleitoral, os índices usam como a agregação máxima os estados, ou seja, os estados, como distritos eleitorais, são tratados independentemente uns dos outros. Dessa forma, o índice deduz dos votos observados para um dado candidato a votação esperada dada a distribuição de eleitores nos municípios de seu respectivo estado.

Como discutido, o pressuposto é que se um candidato decide concentrar seus recursos em apenas alguns municípios, seu desempenho eleitoral nesses municípios deveria ser maior que aquele esperado nesses municípios sem o emprego desses recursos. Assim, de um modo geral, os indicadores de concentração refletiriam os investimentos políticos em geral - estratégias eleitorais - realizados pelos candidatos.

Para retomar e explorar o componente geográfico da concentração eleitoral, uma maneira de analisar o nível de concentração é fazer variar o tamanho da sua unidade de análise; neste caso, um dos obstáculos a serem contornados é encontrar unidades de análise que atendam a quatro condições. A primeira é que não ultrapassem as fronteiras de cada estado, ou seja, o limite territorial deve respeitar o limite dos distritos eleitorais. A segunda condição é que as unidades maiores resultem de agregações similares das unidades menores; esta condição implica que a variação na escala entre as unidades de análise seja similar através de estados e eleições, permitindo comparações. A terceira é que estas agregações sejam realizadas com municípios contíguos, o que permite explorar a hipótese de que a área de influência do candidato se amplia de forma contígua a partir do município central. Finalmente, a quarta condição é que as unidades de análise não sejam formadas aleatoriamente e representem algum tipo de identidade prévia (política, histórica ou econômica) ${ }^{20}$.

Esta última condição, por ser menos óbvia que as outras, merece atenção adicional por motivos metodológicos e teóricos. Metodologicamente, a não aleatoriedade garante ser possível comparar as unidades de análise através do tempo. Em termos teóricos, a identidade prévia determinada principalmente pela história de inter-relações municipais - seria condição para que o candidato se apresentasse como representante daquela região. De acordo com Cox (1997), as eleições implicam na necessidade de coordenação entre as lideranças políticas, mas 
também entre os eleitores, que precisam evitar a fragmentação de seus votos para influenciar o resultado eleitoral. O argumento aqui é que, similarmente a identidade municipal para o caso dos municípios, a identidade regional funcionaria como "ponto focal" (Schelling, 1960), a ser explorado pelo candidato, e que permitiria a coordenação entre os eleitores da região. Embora a identidade municipal seja mais óbvia dada a estrutura político-administrativa brasileira, não existiriam representantes regionais se os eleitores daquelas regiões não se vissem como tal; a existência dessa identidade é que permitiria a coordenação dos votos dos eleitores nos candidatos da sua região ${ }^{21}$.

Atendendo às quatro condições estabelecidas acima, este artigo utiliza três unidades de análise para avaliar a concentração de votos dos candidatos a deputado federal. A primeira unidade é a agregação municipal usada tradicionalmente pela literatura. Para avaliar graus de concentração mais amplos, as outras duas unidades de análise são as micro e mesorregiões - agregações de municípios - tal como definidas pela última divisão regional do país realizada pelo Instituto Brasileiro de Geografia e Estatística (IBGE) em 1989. Além dos aspectos quantitativos, a divisão do país em micro e mesorregiões considerou aspectos econômicos, sociais e espaciais de integração regional entre os municípios que as compõem ${ }^{22}$.

Além de procurar saber se existe de fato algum grau de concentração, outra questão chave é saber em que nível a concentração ocorre ${ }^{23}$. Deste ponto de vista, é fundamental conhecer a unidade relevante de concentração para entender melhor como a geografia é levada em conta nas estratégias eleitorais. Quanto maior a escala de concentração, mais discutível é o conceito de "voto pessoal". Em outros termos, a microrregião já representaria áreas bastante populosas que, embora contíguas, tornaria discutível os pressupostos de liderança municipal e "voto pessoal", pelo menos tal como na definição de concentração tradicionalmente utilizada pela literatura.

A Tabela 1 calcula o "G" para a distribuição dos votos para deputado federal, com base nas três diferentes unidades de análise definidas a partir de níveis crescentes de agregação espacial de votos e apresentadas nos parágrafos anteriores. Com exceção dos dados referentes às eleições de 1994, o restante dos dados foi retirado do Centro de Política e Economia do Setor Público (Cepesp) (www.fgv.br/cepesp/cepespdata $)^{24}$. 
George Avelino, Ciro Biderman e Glauco Peres da Silva

Tabela 1

G Médio por Diferentes Níveis de Agregação Geográfica e pelo Status na Eleição (1994-2014)

\begin{tabular}{|c|c|c|c|c|c|c|c|c|}
\hline \multirow{2}{*}{ Ano } & \multirow{2}{*}{ Resultado } & \multirow{2}{*}{ Candidatos } & \multicolumn{2}{|c|}{ Município } & \multicolumn{2}{|c|}{ Microrregião } & \multicolumn{2}{|c|}{ Mesorregião } \\
\hline & & & G & Var & G & Var & G & Var \\
\hline \multirow{3}{*}{$\stackrel{*}{\stackrel{*}{\sigma}}$} & Eleito & 266 & 0,125 & $3,61 \mathrm{E}-02$ & 0,204 & $1,24 \mathrm{E}-06$ & 0,218 & 5,35E-09 \\
\hline & Não Eleito & 1264 & 0,210 & 2,39E-05 & 263 & 2,03E-09 & 0,262 & $2,62 \mathrm{E}-12$ \\
\hline & Todos & 1530 & 0,195 & $1,11 \mathrm{E}-03$ & 0,253 & $3,88 \mathrm{E}-08$ & 0,254 & $1,64 \mathrm{E}-10$ \\
\hline \multirow{3}{*}{$\stackrel{\infty}{\circ}$} & Eleito & 513 & 0,119 & $3,96 \mathrm{E}-02$ & 0,177 & $1,34 \mathrm{E}-06$ & 0,209 & $2,61 \mathrm{E}-08$ \\
\hline & Não Eleito & 2842 & 0,219 & $1,61 \mathrm{E}-05$ & 0,255 & 1,47E-09 & 0,251 & $1,53 \mathrm{E}-12$ \\
\hline & Todos & 3355 & 0,203 & 9,37E-04 & 0,243 & 3,24E-08 & 0,244 & $6,12 \mathrm{E}-10$ \\
\hline \multirow{3}{*}{ ฮิ } & Eleito & 513 & 0,104 & $2,36 \mathrm{E}-02$ & 0,157 & 1,57E-06 & 0,193 & $3,39 \mathrm{E}-09$ \\
\hline & Não Eleito & 3685 & 0,228 & $9,56 \mathrm{E}-06$ & 0,264 & $3,26 \mathrm{E}-10$ & 0,252 & $2,11 \mathrm{E}-13$ \\
\hline & Todos & 4198 & 0,213 & $3,60 \mathrm{E}-04$ & 0,251 & $2,38 \mathrm{E}-08$ & 0,245 & $5,08 \mathrm{E}-11$ \\
\hline \multirow{3}{*}{ ષ્ટ } & Eleito & 513 & 0,103 & $3,78 \mathrm{E}-02$ & 0,152 & $9,66 \mathrm{E}-07$ & 0,187 & $4,70 \mathrm{E}-09$ \\
\hline & Não Eleito & 4430 & 0,229 & $3,26 \mathrm{E}-06$ & 0,258 & 2,17E-10 & 0,246 & $3,20 \mathrm{E}-13$ \\
\hline & Todos & 4943 & 0,216 & $4,09 \mathrm{E}-04$ & 0,247 & 1,06E-08 & 0,240 & $5,09 \mathrm{E}-11$ \\
\hline \multirow{3}{*}{ 号 } & Eleito & 513 & 0,095 & $2,25 \mathrm{E}-02$ & 0,141 & 5,50E-07 & 0,178 & $3,50 \mathrm{E}-08$ \\
\hline & Não Eleito & 4373 & 0,239 & $1,80 \mathrm{E}-06$ & 0,267 & $7,27 \mathrm{E}-11$ & 0,252 & $1,77 \mathrm{E}-13$ \\
\hline & Todos & 4886 & 0,224 & $2,50 \mathrm{E}-04$ & 0,253 & 6,12E-09 & 0,244 & $3,86 \mathrm{E}-10$ \\
\hline \multirow{3}{*}{$\underset{⿱ 乛}{\stackrel{N}{N}}$} & Eleito & 513 & 0,091 & $1,52 \mathrm{E}-02$ & 0,136 & $3,30 \mathrm{E}-07$ & 0,168 & 2,19E-09 \\
\hline & Não Eleito & 5664 & 0,221 & $6,00 \mathrm{E}-07$ & 0,244 & $5,13 \mathrm{E}-11$ & 0,229 & $6,16 \mathrm{E}-13$ \\
\hline & Todos & 6177 & 0,211 & $1,05 \mathrm{E}-04$ & 0,235 & 2,32E-09 & 0,224 & $1,56 \mathrm{E}-11$ \\
\hline
\end{tabular}

Fonte: Cepespdata/Tribunal Superior Eleitoral (vários anos).

* 1994 inclui apenas 15 unidades da Federação.

Os resultados da Tabela 1 apontam para alguns desdobramentos interessantes. Como se pode observar, existe uma clara diferença no grau de concentração média entre o grupo dos candidatos eleitos e o dos não eleitos, indicando que a média da concentração para todos os candidatos estava sendo inflada pelos candidatos derrotados nas eleições ${ }^{25}$. Essa diferença entre eleitos e não eleitos é significante a $0,1 \%$ em todos os anos considerados. De um modo geral, portanto, a diferença entre eleitos e não eleitos indica que os candidatos que se encaixam melhor no perfil tradicional de concentração a partir de uma liderança local e votação pessoal tendem a ser derrotados nas eleições. Tal como apurado para caso paulista por Avelino, Biderman e Silva (2012), para tornar-se competitivo, o candidato deve buscar ampliar sua esfera de influência eleitoral. Ao olhar apenas para os aspectos relacionados à 
liderança local, ou ao voto pessoal - muitas vezes singularizando um único município - o pesquisador arrisca-se a perder de vista o quadro mais geral das estratégias eleitorais brasileiras ${ }^{26}$.

Vale destacar que não foi possível obter todos os dados para 1994 na desagregação necessária para construir o índice proposto. Assim, temos apenas 15 estados na análise representando pouco mais da metade dos eleitos analisados nos outros casos. No entanto, a subamostra de 1994 não parece se comportar de maneira distinta das outras eleições. O ano que parece mais particular é 2010 quando, pela primeira vez, o total de candidatos no país cai em relação à eleição anterior. A particularidade dessa eleição é que foi a primeira e a única na qual valeu a fidelidade partidária. De todo modo, 2010 também não afeta a tendência geral observada no período e discutida anteriormente.

A análise dos grupos de eleitos e não eleitos ao longo do tempo também traz resultados interessantes. Dentre os eleitos, salta aos olhos a queda na magnitude da concentração, cujo G cai de 0,125 em 1994 para 0,091 em 2014. Entretanto, embora esta queda na magnitude - 27\% seja notável, estatisticamente não se pode negar a hipótese nula de ausência de diferença ao longo do tempo. Em outras palavras, mesmo que a variação da concentração no interior do grupo dos eleitos tenha sido relativamente grande durante os últimos vinte anos, o número baixo de observações neste grupo - sempre limitado a 513 - não permite que se confirme estatisticamente aquela variação nem mesmo a $10 \%$ de significância.

Situação inversa ocorre no caso do grupo dos não eleitos. Nesse grupo, embora a variação da magnitude da concentração tenha sido relativamente pequena - ela sobe de 0,210 em 1994 para 0,221 em 2014 - ela é estatisticamente significante a $1 \%$; muito provavelmente "puxado" pelo grande número de observações neste grupo. Aliás, a entrada de um número crescente de candidatos provavelmente puxa para baixo tanto a magnitude como a variação da concentração, pois a maioria dos candidatos novos tende a ter poucos votos.

Dado que os candidatos com poucos votos tendem a ser naturalmente mais concentrados - por exemplo, um candidato que obteve apenas um voto terá perfil eleitoral perfeitamente concentrado - estes primeiros resultados podem estar sendo superestimados. Para minimizar este problema, a Tabela 1A no Anexo IV apresenta os mesmos resultados da Tabela 1 ponderando o cálculo do G pelo percentual de votos de 
cada candidato, ou seja, multiplicado pela sua participação na votação total. De fato, observa-se uma queda no $\mathrm{G}$ médio ponderado com relação ao G médio da Tabela 1, reforçando a perspectiva de que candidatos menos votados tendem a ser mais concentrados. O interessante é que o grau de concentração cai para todos os grupos, indicando que mesmo entre os eleitos é possível encontrar candidatos concentrados e com votação relativamente baixa. Da mesma forma, no grupo dos não eleitos seria possível encontrar candidatos cuja distribuição de votos tende a se assemelhar ao grupo dos eleitos ${ }^{27}$. Todas as afirmações anteriores, no entanto, permanecem válidas; ou seja, ponderar o cálculo do $\mathrm{G}$ não altera qualitativamente os resultados (seja em magnitude, seja em significância).

Como sugerido, em termos teóricos, pode ser que o declínio da dominância, motivado pelo aumento da competição eleitoral, leve os candidatos a não procurarem concentrar votos em algum município. Em termos empíricos, os dados do último Censo do IBGE indicam que cerca de $70 \%$ dos municípios brasileiros tem até 20 mil habitantes, um número que representaria em média de 14 mil eleitores. Dada essa distribuição dos eleitores são poucos os municípios com eleitores suficientes para garantir a vitória em uma eleição estadual. Desta forma, não é surpreendente que os candidatos visem regiões, agrupamento de municípios, ao invés de municípios individuais.

Visando explorar esta possibilidade de expansão e concentração regional, as colunas seguintes da Tabela 1 trazem resultados para unidades de análise com nível de agregação maior e menos desiguais entre si: as micro e mesorregiões, tal como definidas pelo IBGE. Este procedimento deveria levar a um aumento natural na concentração. De volta à analogia do dartboard, imagine-se agora que o mapa tem menos regiões, pois as áreas geográficas destas últimas são maiores. Sempre que houver um aumento de área, a probabilidade dos dardos se acumularem em uma única região aumenta. Assim, o fato de que os índices de concentração sejam maiores em microrregiões do que em municípios não quer dizer necessariamente que exista maior concentração nessa escala. A questão é saber quanto maior.

De acordo com a Tabela 1, o primeiro destaque nesta comparação é que, como esperado, a ampliação geográfica da unidade de análise dos municípios para as microrregiões tem o efeito de aumentar a concentração eleitoral, mas este efeito é apenas parcial. A mudança da unida- 
de de análise a microrregião, tal como definida pelo IBGE, resulta em aumento da concentração eleitoral, sugerindo que os candidatos - tanto os eleitos como os não eleitos - concentram seus recursos mais neste tipo de divisão geográfica. Isso quer dizer, por exemplo, que um candidato pode ser votado em vários municípios de uma mesma mesorregião sem ser dominante em nenhum desses municípios. Entretanto, o mesmo não ocorre quando a unidade de análise passa de micro para mesorregião, uma vez que os indicadores de concentração são similares nos dois $\operatorname{casos}^{28}$. Mas, porque a concentração eleitoral aumentaria somente para se muda de município para microrregiões, mas não quando se muda de micro para as mesorregiões?

No que tange às estratégias eleitorais, os dados indicam que os candidatos ao saírem das microrregiões não procurariam áreas contíguas, $\mathrm{o}$ que seria capturado pelo aumento da concentração nas mesorregiões, mas outras microrregiões mais distantes e fora da mesorregião de origem, ou então municípios dispersos em outras mesorregiões. Obviamente, um teste mais estrito para esta hipótese, envolveria estudos qualitativos mais densos sobre as atividades dos parlamentares, tal como o realizado por Fenno (1978), e a análise mais detalhada da concentração de votos através das eleições. Finalmente, em termos práticos, os resultados sugerem que as propostas de introdução do voto distrital encontrariam resistências por parte da maioria dos parlamentares.

Mais especificamente, estes resultados, novamente, contrariam a abordagem do voto pessoal e liderança local que esperaria uma expansão contígua a partir do núcleo maior de influência. Embora explicações para estes resultados estejam além dos objetivos deste trabalho, seria possível sugerir a hipótese de que a integração existente nas microrregiões facilitaria a coordenação dos eleitores e a consequente concentração de votos, tal como discutido. Ainda que anedoticamente, esta hipótese teria alguma base quando se verifica que vários deputados são conhecidos mais como representantes regionais do que municipais. Este raciocínio não seria válido para as mesorregiões, cuja extensão territorial dificultaria a integração mais densa entre os municípios que a compõe. Em suma, a integração das atividades dos municípios da região poderia facilitar a coordenação de seus eleitores e a concentração dos votos em candidatos que seriam representativos daquela região; mas, isso valeria apenas para um espaço territorial mais limitado. 


\section{CONCLUSÃO E DESENVOLVIMENTOS FUTUROS}

A fraqueza dos partidos políticos, a possível existência de "distritos informais", e suas consequências sobre a atuação dos parlamentares, tem sido objeto de muita discussão recente na ciência política brasileira. De acordo com a teoria, se os parlamentares apresentam perfil de voto mais concentrado, sua "conexão eleitoral" os fará privilegiar políticas públicas mais fragmentadas, o chamado pork, como forma beneficiar seus respectivos eleitorados. Portanto, mais de vinte anos depois da primeira tentativa realizada por Barry Ames, surpreende a pequena quantidade de trabalhos procurando medir de forma mais sistemática o perfil eleitoral dos nossos parlamentares.

Um dos motivos da ausência desta preocupação talvez esteja relacionado ao fato de que boa parte trabalhos que investigam a conexão eleitoral brasileira, abre mão de uma definição mais profunda do "perfil eleitoral" dos deputados e procura apenas estabelecer se estes últimos priorizam os locais onde foram votados quando tem oportunidade de influenciar as políticas públicas, tal como no caso mais explícito das emendas parlamentares ${ }^{29}$.

Se o uso desta definição mais simples não prejudica necessariamente as inferências sobre as preferencias dos parlamentares sobre a alocação das políticas públicas em determinado município, essa definição certamente obscurece a discussão conceitual sobre o perfil eleitoral dos candidatos. Singularizar um município representa deixar de lado os aspectos geográficos mais amplos da votação do candidato e reforça abordagens que partem de conceitos tais como "voto pessoal", "liderança local", que subentendem relações interpessoais de caráter mais localizado.

Este artigo procura retomar a discussão sobre a existência de um perfil eleitoral dos parlamentares, ao ampliar a aplicação o índice de concentração proposto em Avelino, Biderman e Silva (2011) - antes restrito ao estado de São Paulo - para o conjunto dos estados brasileiros. Esta ampliação permitiu avaliar padrões comuns de estratégias eleitorais para os candidatos a deputado federal de todo o país.

O principal achado destas análises, confirmando o encontrado para o caso de São Paulo, foi a grande diferença nos indicadores de concentração entre os candidatos que conseguem se eleger e os que falham na tentativa. Em outras palavras, os candidatos eleitos apresentam um grau de concentração eleitoral muito menor que os não eleitos, sugerindo uma dispersão de votos maior do que aquela pressuposta por 
conceitos como "voto pessoal" e outras referencias à uma concentração limitada geograficamente. Uma candidatura para ser vitoriosa, portanto, ainda que possa ter por origem uma liderança localizada, supõe alguma dispersão da votação do candidato pelo estado.

Neste sentido, outro achado relevante é que a concentração eleitoral tende a ser regional. Esse resultado indica que, inicialmente, o esforço de desconcentração de um candidato o levaria a avançar sobre os municípios no entorno do município onde tivesse alguma vantagem comparativa. No entanto, este esforço de desconcentração não segue de forma necessariamente contígua, pois não há diferença significativa quando se compara a concentração eleitoral nas micros e nas mesorregiões. Em outras palavras, após conquistar apoio na microrregião, o candidato ou começa a dispersar geograficamente seus esforços ou "salta" para outra microrregião. Assim, tudo o que se pode afirmar é que a microrregião é a unidade máxima de concentração.

Não faz parte dos objetivos desse artigo realizar essa decomposição entre se concentrar em microrregiões relativamente distantes entre si ou se concentrar em uma determinada microrregião e se dispersar no resto do território. Certamente essa seria uma linha relevante de pesquisas futuras; depois de conquistar os municípios do entorno do local onde detinha alguma vantagem comparativa o candidato opta por se dispersar ou por procurar outra microrregião relativamente distante? Observa-se os dois comportamentos ao longo das eleições? Se ambos os comportamentos são observados, qual a diferença entre os dois grupos? A resposta a essas perguntas revela muito da estratégia eleitoral dos candidatos permitindo um aprofundamento na compreensão do comportamento territorial dos candidatos com consequências sobre todo o sistema eleitoral.

Uma consequência importante deste achado para a especificação do perfil eleitoral e da conexão eleitoral deve ser a mudança do foco para os mecanismos que permitem certos candidatos dispersarem suas áreas de influência. Uma pista interessante para a compreensão destes mecanismos foi sugerida por Avelino, Biderman e Barone (2012) que avaliam o impacto das eleições para prefeito na performance dos partidos nas eleições proporcionais para deputado federal dois anos depois. O resultado indica que prefeitos são bastante relevantes na atuação dos deputados do seu partido. Assim, a estratégia de dispersão ou mesmo de eleição de um novo município não seria aleatória, mas determinada pelo apoio dos prefeitos do partido do candidato ou por outra liderança local relevante. 
Outro ponto importante é analisar se utilização de estratégias de concentração pelos candidatos varia entre os estados brasileiros. Por exemplo, a relação entre os incentivos ao emprego de estratégias de concentração eleitoral com algumas variáveis conhecidas na literatura - tais como a volatilidade eleitoral e a magnitude do distrito - ainda está por ser explorada empírica e teoricamente.

Além disso, o fato de que há heterogeneidade dentro de cada grupo (eleitos e não eleitos). Isso significa que, apesar de eleitos em média apresentarem grau de concentração mais baixo, existem certamente eleitos concentrados e não eleitos dispersos. Neste trabalho foi explorada apenas a diferença entre as médias dos dois grupos, deixando em aberto a exploração das diferenças entre eles ao longo da distribuição como um todo. Por exemplo, a discussão da Tabela 1A (Anexo 4) com a ponderação dos votos revela que seria possível encontrar um candidato eleito e outro não eleito para qualquer grau de concentração, o que provavelmente vai depender do desempenho do partido/ coligação do candidato. Qual a proporção de eleitos e não eleitos dispersos? Se a maioria dos eleitos for dispersa, o impacto do voto distrital sobre o status quo seria enorme. Qual a probabilidade de um deputado concentrado se eleger? É maior ou menor do que a de um disperso? Há um grau de dispersão "ótimo"? Essas são questões que poderiam ser respondidas analisando-se a diferença entre eleitos e não eleitos ao longo de toda a distribuição.

Em resumo, o que esse artigo procura mostrar é que a ideia de concentração eleitoral associada a uma liderança local e ao "voto pessoal" não apresenta aderência aos dados. Em geral, os votos dos candidatos eleitos não são concentrados, pelo menos não nos termos supostos pela literatura. A concentração eleitoral parece ser uma estratégia de candidatos entrantes no sistema que precisam se desconcentrar para se elegerem. Assim, a concentração eleitoral não deixa de ser uma estratégia eleitoral; mas, certamente, não é a estratégia utilizada pela maioria dos eleitos. A decisão de concentrar esforços eleitorais é estratégia pontual, ou resposta a situações particulares que tornem a concentração mais efetiva. Certamente, explicar quando e porque esta decisão é tomada, é algo que precisa ser explorado para se poder avançar teórica e empiricamente sobre esta questão.

(Recebido para publicação em setembro de 2014)

(Reapresentado em março de 2016)

(Aprovado para publicação em agosto de 2016) 


\section{NOTAS}

1. Deste ponto de vista, o trabalho de Nunes Leal (1949) pode ser considerado o primeiro alarme sobre a inadequação entre o sistema de representação proporcional e a estrutura social predominantemente agrária da época. Soares (1973 e 2001), entre outros autores deste período posterior, aborda os efeitos da transformação daquela estrutura social em direção à maior urbanização sobre a competição partidária. Para uma visão mais pessimista sobre os efeitos da urbanização sobre a representação proporcional brasileiro pós-1945, ver Britto (1965). Uma ótima revisão deste debate pode ser encontrada em Carvalho (2003).

2. Cox e Thies (1998) chamam esta questão de "product differentiation problem", ou seja, a necessidade dos candidatos de se diferenciarem não apenas dos candidatos de outros partidos, mas também do seu próprio. Sobre a questão do voto pessoal em perspectiva comparada ver também Carey e Shugart (1995).

3. "Campaigning for legislative seats in Brazil is a competition for space. This space can be ideological (like the 'spatial modeling' literature in political science), but more often space really means physical space. Candidates seek municipalities whose voters and/or leaders will give them support" (Ames, 2001:74).

4. Para o tema da conexão eleitoral, a referência clássica é Mayhew (1974). Para o caso brasileiro, além de Ames, uma referência obrigatória é o trabalho de Carvalho (2003).

5. A definição desses espaços, é claro, vai depender do histórico de atividades políticas de cada candidato.

6. Esta expectativa parece se corroborada por Carvalho (2009) que aponta para a sub-representação das grandes áreas metropolitanas. Esta sub-representação seria motivada pela intensa disputa entre candidatos nessas regiões, dispersando a votação.

7. Dados das eleições de 2010 indicam que apenas 77, dos então 5.565 municípios brasileiros, atenderiam a esta restrição.

8. "Na medida em que os municípios se tornam mais distantes, o reconhecimento do nome diminui e os custos de campanha aumentam" (Ames, 1995a:418). Embora sem a conotação geográfica empregada por Ames, a idéia de círculos para expressar diferentes tipos de relação com os eleitores já havia sido explorada por Fenno (1979).

9. Outros autores, antes de Ames, haviam enfatizado a importância da relação entre concentração e contiguidade, importante para medir o grau de "distritalização" das campanhas. Por exemplo, Dias (1991) define como concentrados, os candidatos que obtiveram pelo menos $50 \%$ dos votos em duas zonas eleitorais contíguas.

10. Ver, entre outros, Kinzo (2003 e 2004) e Carvalho (2003).

11. Para uma discussão mais detalhada de alguns destes indicadores, ver Avelino, Biderman e Silva (2011).

12. Na verdade, a concentração, com o seu pressuposto do voto pessoal, não seria necessária para a maioria das análises sobre a conexão eleitoral. Neste caso, simplesmente se avaliaria se os deputados federais enviam recursos para os municípios onde foram bem votados.

13. Assim como o resto da literatura, assume-se que qualquer candidato possui um estoque limitado de recursos - entendidos de maneira ampla - para aplicar na campanha 


\section{George Avelino, Ciro Biderman e Glauco Peres da Silva}

e deve fazer opções sobre como e, principalmente, onde aplicar estes recursos. Estas escolhas definiriam a estratégia eleitoral do candidato, que poderia ser inferida através da análise da distribuição dos votos.

14. Para aplicações do índice $G$ na literatura sobre economia regional, ver, entre outros: Fuchs (1962); Enright (1990); Ellison e Glaeser (1997); Dumais, Ellison e Glaeser (2002); Ellison, Glaeser e Kerr (2010).

15. O Anexo 1 discute e compara o uso do $G$ na análise da distribuição dos empregos em determinado setor da indústria e na análise da distribuição de votos.

16. No caso mais extremo, todos os oito deputados federais eleitos pelo Distrito Federal seriam considerados como perfeitamente concentrados.

17. Para maiores explicações sobre o cálculo da variância, ver o Anexo 3.

18. Embora o princípio seja o mesmo, ou seja, comparar votos obtidos com votos esperados, utilizar a subtração, tal como no cálculo do $G$, tornaria mais difícil a leitura dos dados. Para mais detalhes sobre o QL, ver Isard (1960).

19. Seguindo a mesma terminologia usada anteriormente: $\mathrm{QL}=(\mathrm{vdm} / \mathrm{vd}) /(\mathrm{vm} / \mathrm{v})$.

20. Uma possibilidade natural seria o uso das zonas eleitorais como unidade de análise. Entretanto, segundo o TSE, as áreas geográficas das zonas eleitorais são definidas a partir do simples agrupamento de eleitores vizinhos e administrados por um cartório eleitoral. As zonas eleitorais têm um número determinado de eleitores, de forma que uma nova zona é criada na medida em que aquele limite é atingido. Como uma zona pode abranger desde a parcela do eleitorado de um grande município até englobar os eleitores de mais de um município pequeno, esta característica fere segunda condição sobre a escala entre os níveis de análise. Ademais, ao seguir apenas um critério quantitativo de eleitores, sem maiores preocupações com aspectos econômicos e sociais, a definição das zonas eleitorais, o emprego desta unidade de análise contrariaria a quarta condição.

21. Embora as identidades regionais eleitorais sejam criação de atores políticos, neste trabalho as assumimos como dadas.

22. Segundo o IBGE (1990:8) a mesorregião é uma região coesa socialmente, ambientalmente e com uma rede de comunicação e de articulação entre os municípios que a compõe. As microrregiões são parte das mesorregiões com especificidades em termos de estrutura de produção ou da forma de relação predominante no mercado de trabalho.

23. Indo além dos objetivos deste artigo, como a divisão foi realizada antes do período em análise, mesmo que a construção dessas regiões possa ter sido objeto de intervenção política anterior, pode-se assumir que estas são áreas consideradas pelos candidatos antes das eleições, não sendo resultado da intervenção dos políticos eleitos após 1994. Diferente de Ames, que utiliza o "I" de Moran para construir espaços de concentração eleitoral ex post, aqui se tenta avançar na definição de regiões, cujas características ex ante, as definiriam como potencialmente concentráveis e, portanto, objeto dos investimentos eleitorais dos candidatos. Uma vez eleitos, os deputados procurariam concentrar recursos nessas regiões, o que potencialmente reforçaria a desigualdade entre áreas eleitoralmente concentráveis e áreas não concentráveis, ou seja, micro e mesorregiões poderiam se diferenciar entre si, quanto a serem objeto de investimentos eleitorais. 
24. Exceto no caso da delimitação das micro e mesorregiões - especificadas pelo IBGE e incluídas no Cepesdata - todas as outras informações foram chanceladas pelo TSE, através do seu Repositório de Dados Eleitorais (http: / / www.tse.jus.br/eleicoes / estatisticas/repositorio-de-dados-eleitorais). A tabela no Anexo 2 mostra a distribuição dos municípios, micro e mesorregiões por estado.

25. Em outra tabela, foi separado o grupo dos candidatos suplentes - ou seja, os não eleitos de partidos que elegeram pelo menos um candidato. Verificou-se que este grupo não é muito diferente do grupo dos não eleitos em geral, que agrega também os não eleitos de partidos que não elegeram nenhum candidato. Os não eleitos, portanto, apresentam perfil similar e podem ser agregados em uma única categoria, não importando se pertencem a partidos que se desempenharam melhor eleitoralmente ou não.

26. Possivelmente, o fato de o candidato ser mais conhecido na região onde mora responde por esta concentração inicial. Para mais detalhes sobre os atalhos utilizados pelos eleitores para decidir seu voto, ver Avelino e Biderman (2009); Bowler, Donovan e Snipp (1993); Rennó (2009); Shugart et al. (2009).

27. Embora estes aspectos possam levantar questões interessantes sobre a fronteira que separa os últimos candidatos eleitos dos primeiros não eleitos, essas questões fogem ao escopo deste artigo.

28. Curiosamente, ou não, o número de microrregiões é consideravelmente próximo do número de candidatos nos estados; para maiores detalhes, ver o Anexo 2.

29. A exceção mais notável é o trabalho de Carvalho (2003) que procura determinar o perfil eleitoral dos eleitos para explorar a conexão eleitoral; mas, este autor não problematiza os indicadores de concentração propostos por Ames. Para maiores detalhes sobre as limitações dos indicadores de concentração utilizados pela literatura, ver Avelino, Biderman e Silva (2011). 


\section{REFERÊNCIAS BIBLIOGRÁFICAS}

AMES, Barry. (1995a), "Electoral Strategy under Open-List Proportional Representation". American Journal of Political Science, vol. 39, no 2, pp. 406-433.

(1995b), “Electoral Rules, Constituency Pressures, and Pork Barrel: Bases of Voting in Brazilian Congress". The Journal of Politics, vol. 57, no 2, pp. 324-343.

. (2001), The Deadlock of Democracy in Brazil. Michigan, The University of Michigan Press.

AVELINO, George; BIDERMAN, Ciro. (2009), “Obras e Votação Municipal dos Candidatos a Deputado Federal em São Paulo", in M. Inácio e L. Rennó (orgs.), Legislativo Brasileiro em Perspectiva Comparada. Belo Horizonte, Ed. UFMG.

AVELINO, George; BIDERMAN, Ciro; SILVA, Glauco P. (2011), "A Concentração Eleitoral nas Eleições Paulistas: Medidas e Aplicações". DADOS - Revista de Ciências Sociais, vol. 54, no 2, pp. 319-347.

AVELINO, George; BIDERMAN, Ciro; BARONE, Leonardo. (2012), “Articulações Intrapartidárias e Desempenho Eleitoral no Brasil". DADOS - Revista de Ciências Sociais, vol. 55, no 4, pp. 987-1013.

BENAVID-VAL, Avrom. (1991), "Economy Composition Analysis", in Regional and Local Economic Analysis for Practioners. New York, Praeger, pp. 67-76.

BOWLER, Shaun; DONOVAN, Todd; SNIPP, Joseph. (1993), “Local Sources of Information and Voter Choice in State Elections: Microlevel Foundations of the 'Friends and Neighbors' Effect". American Politics Quarterly, vol. 21, no 4, pp. 473-489.

BRITTO, Luiz Navarro de. (1965), "A Representação Proporcional". Revista Brasileira de Estudos Políticos, no 19, pp. 237-256.

CAIN, Bruce; FEREJOHN, John; FIORINA, Morris. (1987), The Personal Vote: Constituency Service and Electoral Independence. Cambridge, Harvard University Press.

CAREY, John; SHUGART, Matthew S. (1995), "Incentives to Cultivate a Personal Vote". Electoral Studies, vol.14, no 4, pp. 417-439.

COX, Gary W. (1990), "Centripetal and Centrifugal Incentives in Electoral Systems". American Journal of Political Science, vol. 34, no 4, pp. 903-935.

(1997), Making Votes Count; Strategic Coordination in the Worlds Electoral Systems. Cambridge, Cambridge University Press.

. (2005), "Electoral Institutions and Political Competition; Coordination, Persuasion and Mobilization", in C. Menard e E. E. Shirley (eds.), Handbook of New Institutional Economics. Springer.

; SHUGART, Matthew S. (1996), "Strategic Voting under Proportional Representation". Journal of Law, Economics, \& Organization, vol. 12, no 2, pp. 299-324.

; THIES, Michael F. (1998), "The Cost of Intraparty Competition: The Single, Nontransferable Vote and Money Politics in Japan". Comparative Political Studies, vol. 31, no 3, pp. 267-291.

CARVALHO, Nelson R. de. (2003), E no Início Eram as Bases. Rio de Janeiro, Ed. Revan. 
. (2009), “Geografia Política das Eleições Congressuais; a Dinâmica da Representação das Áreas Urbanas e Metropolitanas no Brasil”. Cadernos da Metrópole, vol. 11, no 22, pp. 367-384.

CHO, Eungchum; CHO, Moon Jung. (2008), "Variance of Sample Variance", in Survey Research Methods Section. American Statistical Association.

DIAS, José L. M. (1991), “Legislação Eleitoral e Padrões de Competição Político-Partidária", in O. B. Lima Jr. (org.), Sistema Eleitoral; Teoria e Prática. Rio de Janeiro, Rio Fundo Ed, pp. 65-95.

DUMAIS, Guy; ELLISON, Glenn; GLAESER, Edward L. (2002), “Geographic Concentration as a Dynamic Process". Review of Economics and Statistics, vol. 84, pp. 193-204.

ELLISON, Glenn; GLAESER, Edward L. (1994), "Geographic Concentration in U. S. Manufacturing Industries: A Dartboard Approach". NBER Working Paper, no 4.840.

. (1997), "Geographic Concentration in U.S. Manufacturing Industries: A Dartboard Approach". Journal of Political Economy, vol. 105, no 5, pp. 889-927.

; KERR, William R. (2010), “What Causes Industry Agglomeration? Evidence from Coagglomeration Patterns". American Economic Review, vol. 100, № 3, 1195-1213.

ENRIGHT, Michael. (1990), Geographic Concentration and Industrial Organization. Tese (Doutorado), Harvard University.

FENNO, Richard F. (1978), Home Style; House Members in Their Districts. Little, Brown.

FLORENCE, P. Sargan. (1948), Investment, Location and Size of Plant. A Realistic Inquiry into the Structure of British and American Industries. London, Cambridge University Press.

FLEISCHER, David V. (1976), “Concentração e Dispersão Eleitoral; Um Estudo da Distribuição Geográfica do Voto em Minas Gerais (1966-1974)”. Revista de Ciência Política, vol. 19, no 3, pp. 15-36.

. (1981), “Condições de Sobrevivência da Bancada Federal Mineira em Eleições Distritais". Revista Brasileira de Estudos Políticos, no 53, pp. 153-181.

FUCHS, Vitor. (1962), Changes in the Location of Manufacturing in the US since 1929. New Haven, Yale University Press.

IBGE (Instituto Brasileiro de Geografia e Estatística). (1990), Divisão do Brasil em Mesorregiões e Microrregiões Geográficas. Rio de Janeiro, IBGE.

INDJAIAN, Maria L. (1981), Análise Preliminar da Bancada Federal Paulista Eleita pelo MDB em 1978. São Paulo, Relatório parcial de pesquisa apresentado à FAPESP.

ISARD, Walter. (1960), Methods of Regional Analysis; an Introduction to Regional Science. Cambridge, Massachusetts Institute of Technology Press and Wiley.

KINZO, Maria D. A. (1989), “A Bancada Federal Paulista de 1986: Concentração ou Dispersão do Voto?", in M. T. Sadek (org.), Eleições 1986. São Paulo, Ed. Vértice, pp. 89-100.

KINZO, Maria D. A.; BORIN, Ivan; MARTINS Jr., José P. (2003), Padrões de Competição Eleitoral na Disputa para a Câmara Paulistana, 19992-2000. Novos Estudos CEBRAP, no 65 , pp. 45-56.

DADOS - Revista de Ciências Sociais, Rio de Janeiro, vol. 59, no 4, 2016 


\section{George Avelino, Ciro Biderman e Glauco Peres da Silva}

KINZO, Maria. D. A.; MARTINS Jr., José P.; BORIN, Ivan. (2004), “Patrones de Competencia Electoral en la Disputa por la Camara de Diputados em Brazil (1994-2002)". America Latina Hoy, no 38, pp. 143-162.

LAMOUNIER, Bolívar. (1982), “A Representação Proporcional no Brasil: Mapeamento de um Debate". Revista de Cultura e Política, no 7, pp. 5-42.

MAINWARING, Scott. (1991), "Politicians, Parties, and Electoral Systems: Brazil in Comparative Perspective". Comparative Politics, vol. 24, no 1, pp. 21-43.

. (1999). Rethinking Party Systems in the Third Wave of Democratization: The Case of Brazil. Stanford, Calif., Stanford University Press.

MAYHEW, David R. (1974), Congress: The Electoral Connection. Yale University Press.

NUNES LEAL, Vitor. (1976), Coronelismo, Enxada e Voto: O Município e o Regime Representativo no Brasil. São Paulo, Alfa-Ômega.

RENNÓ, Lúcio. (2009), “Atalhos Cognitivos em Contextos Eleitorais Complexos”, in M. Inácio e L. Rennó (orgs.), Legislativo Brasileiro em Perspectiva Comparada. Belo Horizonte, Ed. UFMG, pp. 237-269.

SCHELLING, Thomas C. (1960), The Strategy of Conflict. Cambridge, Harvard University Press.

SHUGART, Matthew S.; VALDINI, Melody E.; SUOMINEN, Kati. (2005), “Looking for Locals: Voter Information Demands and Personal Vote-Earning Attributes of Legislators under Proportional Representation". American Journal of Political Science, vol. 49, no 2, pp. 437-449.

SOARES, Gláucio A. D. (1973), Sociedade e Política no Brasil. São Paulo, Difusão Européia do Livro.

(2001), A Democracia Interrompida. Rio de Janeiro, FGV Editora. 


\section{ANEXO 1}

Comparação entre o Emprego do G na Análise da Economia Regional (Ellison E Glaeser) e na Distribuição do Voto

\begin{tabular}{|l|l|}
\hline Ellison \& Glaeser & Por Deputado (d) \\
\hline i = área geográfica & $\mathrm{m}=$ Município \\
\hline Indústria = setor da indústria & $\mathrm{d}=$ Candidato \\
\hline Employment = Emprego & Voto \\
\hline $\begin{array}{l}\text { sãi = proporção do emprego da indústria } \\
\text { na área i sobre o total de empregos na } \\
\text { indústria (Emprego indústria i/Emprego } \\
\text { na indústria) }\end{array}$ & $\begin{array}{l}\text { Proporção de votos do candidato no } \\
\text { município m sobre o total de votos do } \\
\text { candidato (Vdm/Vd) }\end{array}$ \\
\hline $\begin{array}{l}\text { xãi = proporção do emprego na área i } \\
\text { sobre o emprego agregado } \\
\text { (Emprego na área i/Emprego agregado) }\end{array}$ & $\begin{array}{l}\text { Proporção do voto total no município m } \\
\text { sobre o total de votos agregados } \\
\text { (Vm/V) }\end{array}$ \\
\hline
\end{tabular}

Tal como discutido no texto, o objetivo de Elisson e Glaeser (1994 e 1997) era analisar o grau de concentração do emprego em determinada indústria. Dessa forma, o mapa dos Estados Unidos foi dividido segundo algum critério que defina as áreas " $\mathrm{i}$ " - estados, por exemplo para tentar saber se certos setores da indústria concentravam geograficamente seus investimentos e, portanto, seus empregos. Da mesma, forma, o uso do "G" para a análise eleitoral, divide o mapa por algum critério - municípios, por exemplo - na tentativa de analisar se os candidatos concentram geograficamente seus investimentos e, portanto, seus votos. 


\section{ANEXO 2}

Brasil 2010

Distribuição dos Municípios, Micro e Mesorregiões por UF

\begin{tabular}{|c|c|c|c|}
\hline UF & Municípios & Microrregiões & Mesorregiões \\
\hline $\mathrm{AC}$ & 22 & 5 & 2 \\
\hline AL & 102 & 13 & 3 \\
\hline $\mathrm{AM}$ & 62 & 13 & 4 \\
\hline $\mathrm{AP}$ & 16 & 4 & 2 \\
\hline BA & 417 & 32 & 7 \\
\hline CE & 184 & 33 & 7 \\
\hline $\mathrm{DF}$ & - & 1 & 1 \\
\hline ES & 78 & 13 & 4 \\
\hline GO & 246 & 18 & 5 \\
\hline MA & 217 & 21 & 5 \\
\hline MG & 853 & 66 & 12 \\
\hline MS & 79 & 11 & 4 \\
\hline MT & 141 & 22 & 5 \\
\hline PA & 144 & 22 & 6 \\
\hline PB & 223 & 23 & 4 \\
\hline PE & 185 & 19 & 5 \\
\hline PI & 224 & 15 & 4 \\
\hline PR & 399 & 39 & 10 \\
\hline $\mathrm{RJ}$ & 92 & 18 & 6 \\
\hline $\mathrm{RN}$ & 167 & 19 & 4 \\
\hline $\mathrm{RO}$ & 52 & 8 & 2 \\
\hline $\mathrm{RR}$ & 15 & 4 & 2 \\
\hline RS & 497 & 35 & 7 \\
\hline SC & 295 & 20 & 6 \\
\hline $\mathrm{SE}$ & 75 & 13 & 3 \\
\hline $\mathrm{SP}$ & 645 & 63 & 15 \\
\hline TO & 139 & 8 & 2 \\
\hline 27 & 5.569 & 558 & 137 \\
\hline
\end{tabular}




\section{ANEXO 3}

\section{Cálculo da Variância do G}

Para calcular a variância do G não utilizamos simplesmente a dispersão dos diversos Gs calculados para cada deputado por três motivos substantivos. Em primeiro lugar, essa medida seria discutível visto que o G já é uma medida de dispersão. Como é conhecido, a variância de uma dispersão não pode ser estimada diretamente como qualquer variância. Por exemplo, a variância da variância não é calculada dessa forma (vide, inter alia, Cho e Cho, 2008). Em outras palavras esse indicador sob diversas circunstâncias seria enviesado.

O segundo problema é que essa medida seria altamente ineficiente. Isso porque para estimar cada $\mathrm{G}$ partimos de milhares de informações cada qual com sua margem de erro. Estaríamos ignorando os erros de cada observação partindo para essa medida agregada. Assim, uma medida que contemplasse todas as observações evidentemente seria muito mais eficiente.

Finalmente, a medida tomada a partir dos microdados permite que se encontre uma variação para cada deputado o que é potencialmente muito relevante para a análise da concentração espacial dos candidatos como discutido na conclusão desse artigo. É possível definir se um deputado é significativamente concentrado ou não a partir dessa medida.

A estimativa de variância para o $G$ pode ser adaptada a partir da Proposição 2 apresentada em Ellison e Glaeser (1994) e escrita como:

$$
\begin{aligned}
& \operatorname{Var}\left[G_{d}\right]=H 2\left(\sum_{m} V_{m}^{2}-2 \sum_{m} V_{m}^{3}+\left(\sum_{m} V_{m}^{2}\right)^{2}\right) \\
& -\sum_{m} V_{d, m}^{4}\left(\sum_{m} V_{d, m}^{2}-4 \sum_{m} V_{d, m}^{3}+3\left(\sum_{m} V_{d, m}^{2}\right)^{2}\right)
\end{aligned}
$$

Em que:

$H^{2}$ é o índice de Herfindahl-Hirshman definido como $H^{2}=\sum_{m} V_{d, m}^{2}$; $V_{d}=v_{d m} / v_{d}$ ou seja a proporção dos votos do deputado no município; $V_{m}=v_{m} / v$ ou seja a proporção dos votos do município no estado. 
Ou seja, usamos maiúsculas para as proporções utilizadas na equação (4) que definiu o índice $G$ para nossos fins. Omitimos uma vez mais o tempo para tornar a notação um pouco mais palatável. Como já havíamos comentado isso significa que teremos um indicador de significância para cada deputado. Estamos, no entanto, preocupados em comparar médias entre grupos distintos. Para isso precisamos somar variâncias.

A forma de somar variâncias de maneira relativamente simples é assumir que o grau de concentração de um deputado é independente do grau de concentração dos demais. Essa hipótese é forte, mas precisamos qualificá-la um pouco mais para não parecer tão forte quanto parece. Não estamos dizendo que a proporção de votos do candidato $i$ no município $m$ é independente da proporção de votos do candidato $j$ nesse mesmo município. O que estamos dizendo é que a decisão de se concentrar ou não é independente da decisão dos demais candidatos. Ainda é um pouco forte a hipótese visto que assumimos que um candidato decide se concentrar em função apenas dos seus "recursos" eleitorais este ponto também é percebido por Ames que ressalta a importância da atuação passada do candidato na definição de suas estratégias eleitorais (Ames, 2001:81-82) - e não observando a decisão de se concentrar ou se dispersar dos demais candidatos.

A partir dessa hipótese, podemos estimar facilmente a variância para um determinado grupo. Imagine que $g=\left\{1,2, \ldots, N_{g}\right\}$ é um grupo de $N_{g}$ candidatos como, por exemplo, o grupo dos candidatos eleitos. Podemos definir o grau de concentração médio para esse grupo $\left(\mathrm{G}^{g}\right)$ como:

$$
G^{g}=\frac{1}{N_{g}} \sum_{d \varepsilon g} G_{d}
$$

Ou seja, simplesmente definimos como grau de concentração do grupo a média simples dos graus de concentração dos deputados desse determinado grupo. Dada essa definição e a hipótese de independência entre os deputados, podemos estimar a variância para o grupo como:

$$
\operatorname{Var}\left[G^{g}\right]=\operatorname{Var}\left[\frac{1}{N_{g}} \sum_{d \varepsilon g} G_{d}\right]=\frac{1}{N_{g}^{2}} \sum_{d \varepsilon g} \operatorname{Var}\left[G_{d}\right]
$$

Portanto, estimamos a variância do grau de concentração de cada deputado a partir de (A.1) e em seguida estimamos a variância para esse grupo a partir de (A.3). 


\section{ANEXO 4}

Tabela 1a

G Médio Ponderado por Diferentes Níveis de Agregação Geográfica e pelo Status na Eleição (1994-2014)

\begin{tabular}{|c|c|c|c|c|c|c|c|c|}
\hline \multirow{2}{*}{ Ano } & \multirow{2}{*}{ Resultado } & \multirow{2}{*}{ Candidatos } & \multicolumn{2}{|c|}{ mun } & \multicolumn{2}{|c|}{ micro } & \multicolumn{2}{|c|}{ meso } \\
\hline & & & G & Var & G & Var & G & Var \\
\hline \multirow{3}{*}{$\begin{array}{l}\text { Бे } \\
\sigma\end{array}$} & Eleito & 266 & 0,059 & $3,61 \mathrm{E}-02$ & 0,116 & $1,24 \mathrm{E}-06$ & 0,132 & $5,35 \mathrm{E}-09$ \\
\hline & Não Eleito & 1.264 & 0,124 & 2,39E-05 & 0,169 & 2,03E-09 & 0,165 & $2,62 \mathrm{E}-12$ \\
\hline & Todos & 1.530 & 0,113 & 1,11E-03 & 0,160 & $3,88 \mathrm{E}-08$ & 0,160 & $1,64 \mathrm{E}-10$ \\
\hline \multirow{3}{*}{$\stackrel{\infty}{\stackrel{2}{\sigma}}$} & Eleito & 513 & 0,053 & $3,96 \mathrm{E}-02$ & 0,091 & $1,34 \mathrm{E}-06$ & 0,121 & $2,61 \mathrm{E}-08$ \\
\hline & Não Eleito & 2.842 & 0,131 & 1,61E-05 & 0,166 & 1,47E-09 & 0,159 & $1,53 \mathrm{E}-12$ \\
\hline & Tod & 3.355 & 0,119 & 9,37E-04 & 0,154 & 3,2 & 0,153 & $6,12 \mathrm{E}-10$ \\
\hline \multirow{3}{*}{ ઠิ } & Eleito & 513 & 0,043 & $2,36 \mathrm{E}-02$ & 0,075 & $1,57 \mathrm{E}-06$ & 0,105 & $3,39 \mathrm{E}-09$ \\
\hline & Não Eleito & 3.685 & 0,139 & $9,56 \mathrm{E}-06$ & 0,176 & $3,26 \mathrm{E}-10$ & 0,161 & $2,11 \mathrm{E}-13$ \\
\hline & Todos & 4.198 & 0,127 & $3,60 \mathrm{E}-04$ & 0,163 & $2,38 \mathrm{E}-08$ & 0,154 & $5,08 \mathrm{E}-11$ \\
\hline \multirow{3}{*}{ ஜั } & Eleito & 513 & 0,045 & $3,78 \mathrm{E}-02$ & 0,074 & $9,66 \mathrm{E}-07$ & 0,103 & 4,70E-09 \\
\hline & Não Eleito & 4.430 & 0,142 & $3,26 \mathrm{E}-06$ & 0,174 & 2,1 & 0,159 & $3,20 \mathrm{E}-13$ \\
\hline & Todos & 4.943 & 0,132 & 4,09E-04 & 0,164 & $1,06 \mathrm{E}-08$ & 0,153 & $5,09 \mathrm{E}-11$ \\
\hline \multirow{3}{*}{$\begin{array}{l}\stackrel{\circ}{\circ} \\
\stackrel{\sim}{\sim}\end{array}$} & Eleito & 513 & 0,039 & $2,25 \mathrm{E}-02$ & 0,064 & $5,50 \mathrm{E}-07$ & 0,096 & $3,50 \mathrm{E}-08$ \\
\hline & Não Eleito & 4.373 & 0,151 & $1,80 \mathrm{E}-06$ & 0,182 & 7,27E-11 & 0,165 & $1,77 \mathrm{E}-13$ \\
\hline & Todos & 4.886 & 0,139 & $2,50 \mathrm{E}-04$ & 0,170 & $6,12 \mathrm{E}-09$ & 0,158 & $3,86 \mathrm{E}-10$ \\
\hline \multirow{3}{*}{$\stackrel{\overrightarrow{2}}{\stackrel{2}{\sim}}$} & Eleito & 513 & 0,038 & $1,52 \mathrm{E}-02$ & 0,063 & $3,30 \mathrm{E}-07$ & 0,089 & 2,19E-09 \\
\hline & Não Eleito & 5664 & 0,138 & $6,00 \mathrm{E}-07$ & 0,164 & $5,13 \mathrm{E}-11$ & 0,147 & $6,16 \mathrm{E}-13$ \\
\hline & Todos & 6177 & 0,130 & $1,05 \mathrm{E}-04$ & 0,155 & 2,32E-09 & 0,143 & $1,56 \mathrm{E}-11$ \\
\hline
\end{tabular}

Fonte: Tribunal Superior Eleitoral (vários anos).

* 1994 inclui apenas 15 Unidades da Federação. 


\section{RESUMO}

A Concentração Eleitoral no Brasil (1994-2014)

Este artigo retoma a apresentação de um novo indicador de concentração eleitoral sugerido por Avelino, Biderman e Silva em artigo publicado em 2011 na Revista DADOS e amplia seu uso para o conjunto dos candidatos do país nas eleições realizadas entre 1994 e 2014. Os resultados mostram de forma sistemática que os candidatos que conseguem se eleger são menos concentrados do que os candidatos derrotados. A originalidade principal reside no fato de que tal achado contraria as teses que assumem o predomínio do voto pessoal nas eleições proporcionais brasileiras.

Palavras-chave: partidos políticos; eleições; estratégias eleitorais; concentração eleitoral

\section{ABSTRACT \\ Geographical Scattering of Votes in Brazilian Elections (1994-2014)}

The following article seeks to expand on a new indicator of the geographical scattering of votes presented by Avelino, Biderman and Silva in an article published in DADOS Journal in 2011, extending its use to encompass candidates in Brazilian elections held from 1994 to 2014. The results systematically demonstrate that support for successful candidates was more scattered than that for defeated candidates, with the article's most original feature lying in the fact that such a finding contradicts theories assuming the predominance of votes for individuals in proportional Brazilian elections.

Key words: political parties; elections; electoral strategies; geographical scattering of votes 


\section{RÉSUMÉ \\ La Concentration Électorale au Brésil (1994-2014)}

Cet article s'intéresse à un nouvel indicateur de concentration électorale proposé par Avelino, Biderman et Silva dans un article publié en 2011 dans la revue DADOS, pour en élargir l'usage à l'ensemble des candidats du pays aux élections tenues entre 1994 et 2014. Les résultats montrent de manière systématique que les candidats qui réussissent à se faire élire jouissent d'une moindre concentration électorale que les candidats battus. La principale originalité réside dans le fait que ces conclusions contrarient les thèses qui soutiennent la prédominance du vote personnel lors des élections proportionnelles brésiliennes.

Mots-clés: partis politiques; élections; stratégies électorales; concentration électorale

\section{RESUMEN}

La Concentración Electoral en Brasil (1994-2014)

Este artículo retoma la presentación de un nuevo indicador de concentración electoral sugerido por Avelino, Biderman y Silva en un artículo publicado en 2011 en la Revista DADOS y amplía su uso al conjunto de los candidatos del país en las elecciones realizadas entre 1994 y 2014. Los resultados muestran de manera sistemática que los candidatos que logran elegirse están menos concentrados que los candidatos derrotados. La originalidad principal está en el hecho de que dicho hallazgo contraría las tesis que asumen el predominio del voto personal en las elecciones proporcionales brasileñas.

Palabras clave: partidos políticos; elecciones; estrategias electorales; concentración electoral 